Review

\title{
A Systematic Study of the Novel Materials used in Solar Cell Technologies, Opportunities and Challenges
}

\author{
${ }^{1}$ Aayush Kumar Choudhary, ${ }^{2}$ Godwin Glivin, ${ }^{2}$ N. Kalaiselvan, ${ }^{3}$ V. Mariappan and ${ }^{4}$ S. Joseph Sekhar \\ ${ }^{1}$ Department of Chemical Engineering, National Institute of Technology Tiruchirappalli, Tamil Nadu, India \\ ${ }^{2}$ Department of Energy and Environment, National Institute of Technology Tiruchirappalli, Tamil Nadu, India \\ ${ }^{3}$ Department of Mechanical Engineering, National Institute of Technology Tiruchirappalli, Tamil Nadu, India \\ ${ }^{4}$ Mechanical Section, Department of Engineering, Shinas College of Technology, Shinas, Sultanate of Oman
}

\author{
Article history \\ Received: 24-08-2020 \\ Revised: 10-10-2020 \\ Accepted: 02-11-2020 \\ Corresponding Author: \\ Aayush Kumar Choudhary \\ Department of Chemical \\ Engineering, National Institute \\ of Technology Tiruchirappalli, \\ Tamil Nadu, India \\ Email: aayush08may@gmail.com
}

\begin{abstract}
This study aims to review the present progress of integrating the PV cell with other prominent mainstream photovoltaic cell materials. The combination of the materials in a thin film electric cell is advantageous due to the reduction within the material usage and therefore the rise in efficiency. Amorphous Silicon ( $\alpha-\mathrm{Si})$, Cadmium Telluride $(\mathrm{CdTe})$ and Copper Indium Gallium Selenide (CIGS) are the three major thin film solar cells technologies. The discussion mainly focuses on the environmental factors, efficiency of the energy production and limitations of the utilization of the technology. The recent progress within the third-generation cells is being reckoned as a pathway to beat the drawbacks and therefore, the concerns regarding the present solar cell technologies. Referring to this situation there are certainly more theoretical analysis than the sensible application of the third-generation solar cells. The need of low-cost, flexible, scalable and lightweight materials has certainly been the key propulsion within the development of the third-generation solar cells. The exploration of those new materials certainly holds the aptitude to enhance the device performance and stability, resulting in its commercialization within the photovoltaic field in the coming years.
\end{abstract}

Keywords: Ecosystem, Solar Energy, Thin Film, Perovskites, Sustainability

\section{Introduction}

The current generation exists in a transitional phase where we realize the impact of the fossil fuels and the other by products laced with a similar origin have on our environment. The greenhouse gas management has been one of our major concerns which owe a majority of their existence to the excessive use of fossil fuels in the domains of energy production. These environmental problems will certainly prolong till the renewable energy resources are not implemented on a sufficiently large scale (Weldekidan et al., 2018). The essence that the climate change is real and the fact that the green house gases contribute to the global warming which has led to the rise of the global average surface temperature by 0.6 degree Celsius since the 1950's. The rising temperature leads to the degradation of the soil, reduced productivity of agricultural land, desertification, acidification of oceans and reduced fresh water resources (Rossati, 2017). The effect of rising temperature has also had an impact on the rising sea and ocean levels due to the melting of the glaciers. On an average a rise of $10-20 \mathrm{~cm}$ in the sea level has been observed on an annual scale as the temperature of the oceans have increased (Weldekidan et al., 2018). The melting of the glaciers have been responsible for the release of a large amount of mercury trapped in the ice into the atmosphere and the other downstream ecosystems (Wang et al., 2020).

The photovoltaic technology has certainly bolstered those efforts as the world moves towards the green energy resources. The photovoltaic technology utilizes the semiconductors to generate energy directly from the solar energy. The energy scientists have been putting in a lot of efforts to improve the efficiency of photovoltaic technology (Kabir et al., 2018). The use of solar panels is definitely not something which has sprung 
up recently but it has been under operation since the 80 's, only in the past decade an exponential rise is observed in the PV market as the cumulative installed capacity reached a total of $402.5 \mathrm{GW}$ in 2017 (Del Pero et al., 2019). The factors such as the exposed solar radiations, ambient temperatures, location of installation, wind kinetics and tiny dust particles i.e., aerosols influence the performance of the commercial solar photovoltaics (Kumar and Chowdhury, 2019).

A global market share of about a $91 \%$ as depicted clearly in the Fig. 1, certainly makes crystalline silicon one of the most important PV technology in the current state of the world. Silicon stands above the rest of the materials used in photovoltaic technology as its stability, abundance and non-toxicity definitely make a case in its favor. It possesses an indirect band gap alongside with an energy gap of around $1.12 \mathrm{eV}$ which places it comfortably in the solar spectrum (Battaglia et al., 2016). The energy conversion efficiency of the c-Si solar cells breached the limit of $25 \%$ which was set way back in 1999. It was unsurpassed for almost 15 years when finally in 2014 we observed a $25.6 \%$ efficiency and almost simultaneously the Panasonic, Japan and the SunPower, USA, reported independent efficiencies of 25.6 and $25 \%$ efficiency respectively (Battaglia et al., 2016; Andreani et al., 2019). An efficiency of over $26 \%$ was observed using a large area $180 \mathrm{~cm}^{2}$ designated area c-Si solar cell with an IBC structure combined with a-Si/c-Si Heterojunction which was prepared using the industrially feasible technologies (Yoshikawa et al., 2017).
The utility of the thin film solar cells has been increasing, credits to the minimal material usage, cost effective synthesis processes and a promising trend with the rising efficiency values (Kowsar et al., 2019). The use of the flexible thin film solar cells such as CIGS, $\mathrm{CdTe}$ and $\alpha-\mathrm{Si}: \mathrm{H}$ received the deserved worldwide attention. The blockage in the growth of market from the current situation of the Si solar cells have been its cost of production as the $\mathrm{Si}$ substrates account for the major cost. One of the prominent ways to tackle that is to use low-cost flexible substrates. Metallic foils, plastic films, flexible glass and paper substrates can also be used as we decide the substrates for the flexible solar cells (Ramanujam et al., 2020). The efficiency of CIGS and CdTe technologies have risen in the past decade or so and in the present market they stand at par with the crystalline $\mathrm{Si}$ solar cell modules. The use of $\alpha-\mathrm{Si}$ has been hindered owing to its low efficiency and light induced degradation, this has restricted its applications in the terrestrial applications. The CIGS and the CdTe modules hold a better future but still the constancy, reliability and the trust from the consumer side is essential before these techniques are integrated in the photovoltaic systems (Lee and Ebong, 2017). The concentration of the absorber layer defects must be minimized to a least possible value in order to set up an enhanced photovoltaic efficiency (Mathur and Singh, 2020). A very generalized model of a thin film PV cell is represented in the Fig. 2.

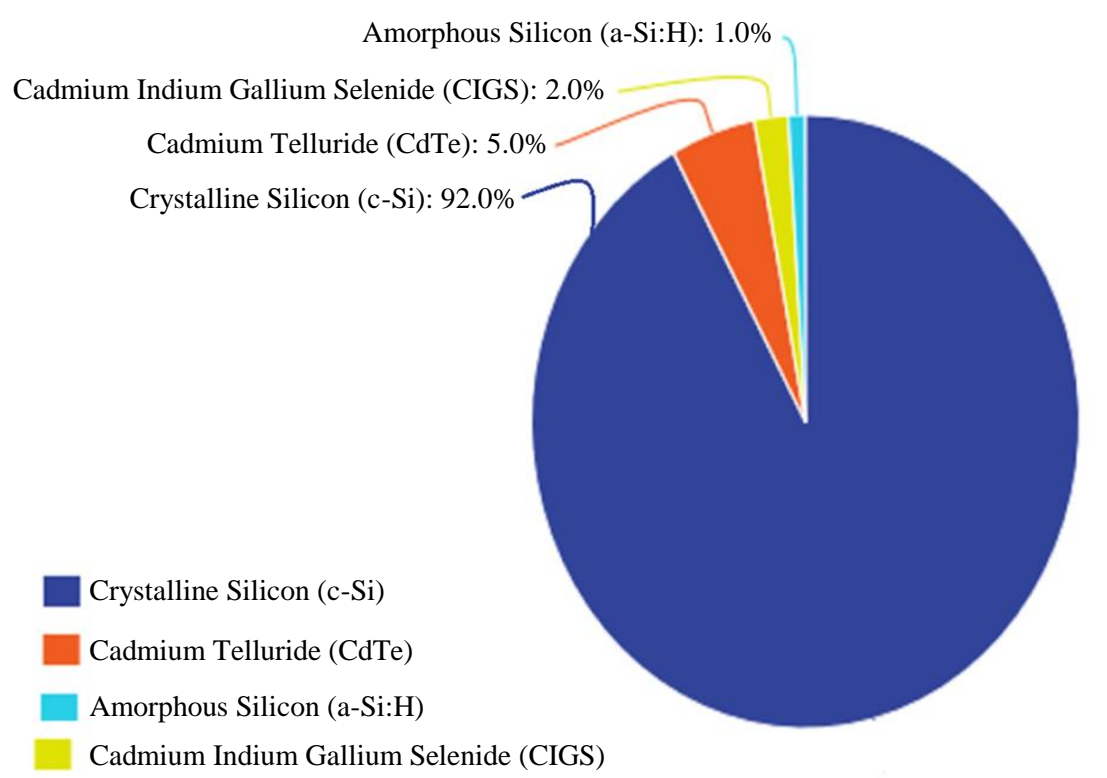

Fig. 1: A graphical representation of the current percentage shares of the PV market by the Silicon and the thin film technologies portraying the domination of the crystalline Silicon Solar cells 

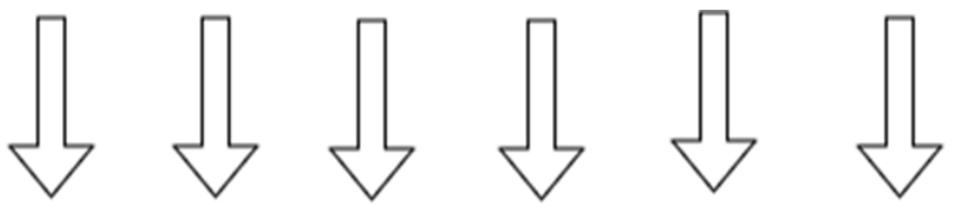

Sun's

rays

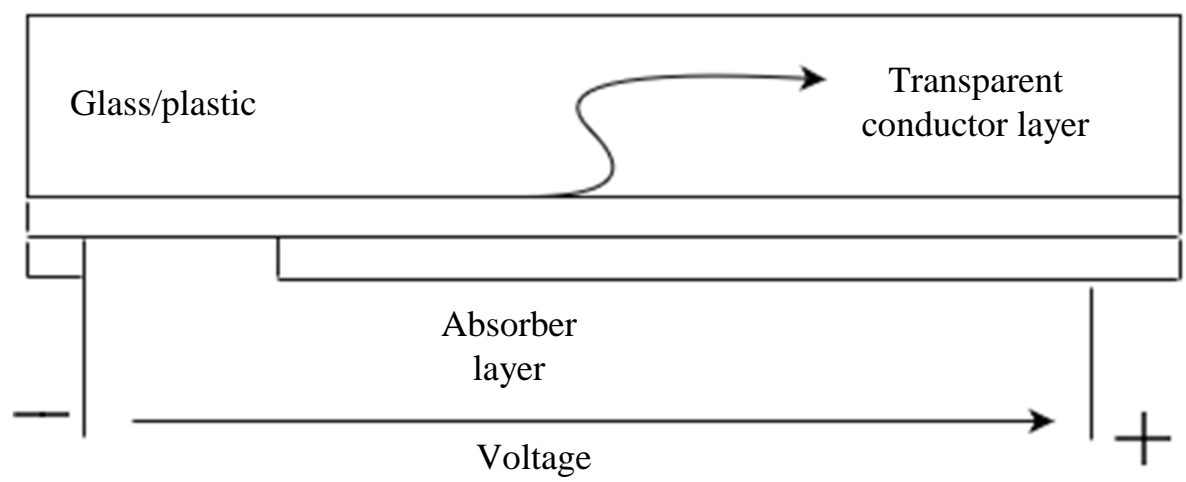

Fig. 2: A generalized thin film PV module which consists of the glass/plastic as a substrate, a transparent conductor and a absorber layer with an applied potential across to distribute the generation across the load

The next generation semiconductors such as the organohalide perovskites, inorganic nanocrystals and organic semiconductors are allowing the generation of the new thin film optoelectronics, alongside with the photovoltaics, light emitting devices and the photodetectors (Fang et al., 2019). The hybrid halide perovskites such as the methylammonium lead iodide (CH3NH3PbI3) garners a lot of attention in the current emerging thin-film PV market have received an immense amount of research interest, such as the methylammonium lead iodide $(\mathrm{CH} 3 \mathrm{NH} 3 \mathrm{PbI} 3)$ garners a lot of attention in the current emerging thin-film PV market, having received an immense amount of research interest. The kesterite mineral based structure refer to the use of Cu2ZnSnS4 (CZTS), Cu2ZnSnSe4 (CZTSe) and their alloys $\mathrm{Cu} 2 \mathrm{ZnSn}(\mathrm{SxSe} 1-\mathrm{x}) 4$. (CZTSSe)being composed of earth abundant and non-toxic elements these have certainly been a major boost to the investments that have gone into these technologies (Wallace et al., 2017).

\section{Evolution of Thin Film Solar Panels}

\section{The $\alpha$-Si Solar Cells}

The use of $\alpha$-Si solar cells is encouraged as it exists as a direct band gap material which in turn improves its absorbance of solar radiations within a few micrometer thin layer which has savings on the amount of the material required in the absorbance layer. The presence of the dangling bonds result in the short minority carrier diffusion lengths and the other abnormal electrical behaviors. The minority charge carrier length can be increased by using the hydrogen passivation which also counters on the presence of the dangling bond densities. However, the fact that the hydrogen passivation leads to the Staebler-Wronski light degradation effect puts the society under pressure to look for proper alternatives (Lee and Ebong, 2017).

An experimental analysis conducted by (Zaidi et al., 2018) on the amorphous silicon solar panels for electrical power generation in the city of Hassi Messaoud, Ouargla where the abundantly available solar energy is harnessed for the electrical power generation well suited due to its geographical location. They observed a direct relation between the incident solar radiations and the power generated. The analysis which was carried on from March to October observed a drop of approximately $20 \%$ in the net power generation in the winter months as compared to that of the c-Si solar panels under similar conditions (Zaidi et al., 2018). The Light Induced Degradation (LID) has been responsible for the efficiency drops that are included in the advertised efficiency values. The Energy Payback time is measured as the time required by the device to produce the same amount of energy as was required in its manufacturing. An experimental analysis by (Huang and $\mathrm{Yu}, 2017)$ with single-crystalline, multi-crystalline and amorphous silicon systems compared their energy payback time and the efficiencies. The efficiencies recorded were 13.2, 14.4 and $6.6 \%$ for multi-crystalline, single-crystalline and amorphous silicon cells respectively with their energy payback time varying between 3-7.4 years thus indicating the sustainability and the environmental friendly nature of the three PV- 
systems. The Energy Payback Time (EPBT) of different materials being used for the generation of solar cells has been depicted in Fig. 3.

\section{CIGS Solar Cells}

Copper Indium Gallium Selenide (CIGS) based solar cells have been recognized on the global scale for the comparable power generation efficiency of $22.8 \%$, similar to what is observed in the case of crystalline silicon(c-Si) solar cells. For the CIGS cells over glass, a graded bandgap high temperature deposition process is needed yet the same has not been established for CIGS over the flexible substrates of polymer which is a low temperature process. The CIGS bandgap can be tuned to match with that of the solar spectrum if we consider chalcopyrite $\mathrm{Cu}(\mathrm{In}, \mathrm{Ga}, \mathrm{Al})(\mathrm{Se}, \mathrm{S}) 2$ alloy system, where the band gap can be varied from $1.04 \mathrm{eV}$ (CuInSe2) to about $3.5 \mathrm{eV}$ (CuAlS2), ranging across the entire spectrum. Similar to the case with the amorphous silicon solar cells the amount of raw materials that are required for the manufacture of the panels can be reduced as it absorbs the most of the solar spectrum within $1 \mathrm{~mm}$ with a thin layer of $2-2.5 \mathrm{~mm}$. The fact that it is a direct bandgap material pushes its absorption coefficient higher as compared to that of the crystalline silicon solar cells which are indirect bandgap semiconductors (Ramanujam and Singh, 2017).
$\mathrm{Cu}(\mathrm{In}, \mathrm{Ga})(\mathrm{S}, \mathrm{Se}) 2$ (CIGS)-based thin film solar cells have certainly evolved as one of the most promising Photovoltaic (PV) technology, with steadily increasing efficiency values which has moved up to $22.6 \%$ for the lab scale researchers (Feurer et al., 2017). The introduction of $K$ into $\mathrm{Cu}$ (In, Ga) (Se, S) 2 (CIGS) absorbers has led to further improved power conversion efficiencies as discussed by (Muzzillo, 2017). The distribution among the grain interiors, boundaries and interfaces go on to affect the effect of $K$. For the CIGS bandgap of $1.14 \mathrm{eV}$, the theoretical efficiency limits are seen around 33.5\%, as stated by (Muzzillo, 2017; Ramanujam and Singh, 2017) which on a practical scale can move up to $25 \%$ from the present $22.8 \%$ by improving on the CIGS absorber properties, reducing the defect density by surface passivation and using a reflector on the rear side to redirect the unused light. Measuring the energy payback with reference to the cost that is incurred per unit of power generation, CIGS is still making efforts to reduce its production cost to below $€ 1 / \mathrm{Wp}$ as compared to $€ 0.75 / \mathrm{Wp}$ as observed in case of amorphous silicon solar cells in spite of the fact that it is at the price that we need to pay for a reduced efficiency of power generation of amorphous silicon (a-Si) as compared to that of CIGS which continues to make strong strides with reference to the efficiency of power generation (Ong et al., 2018).

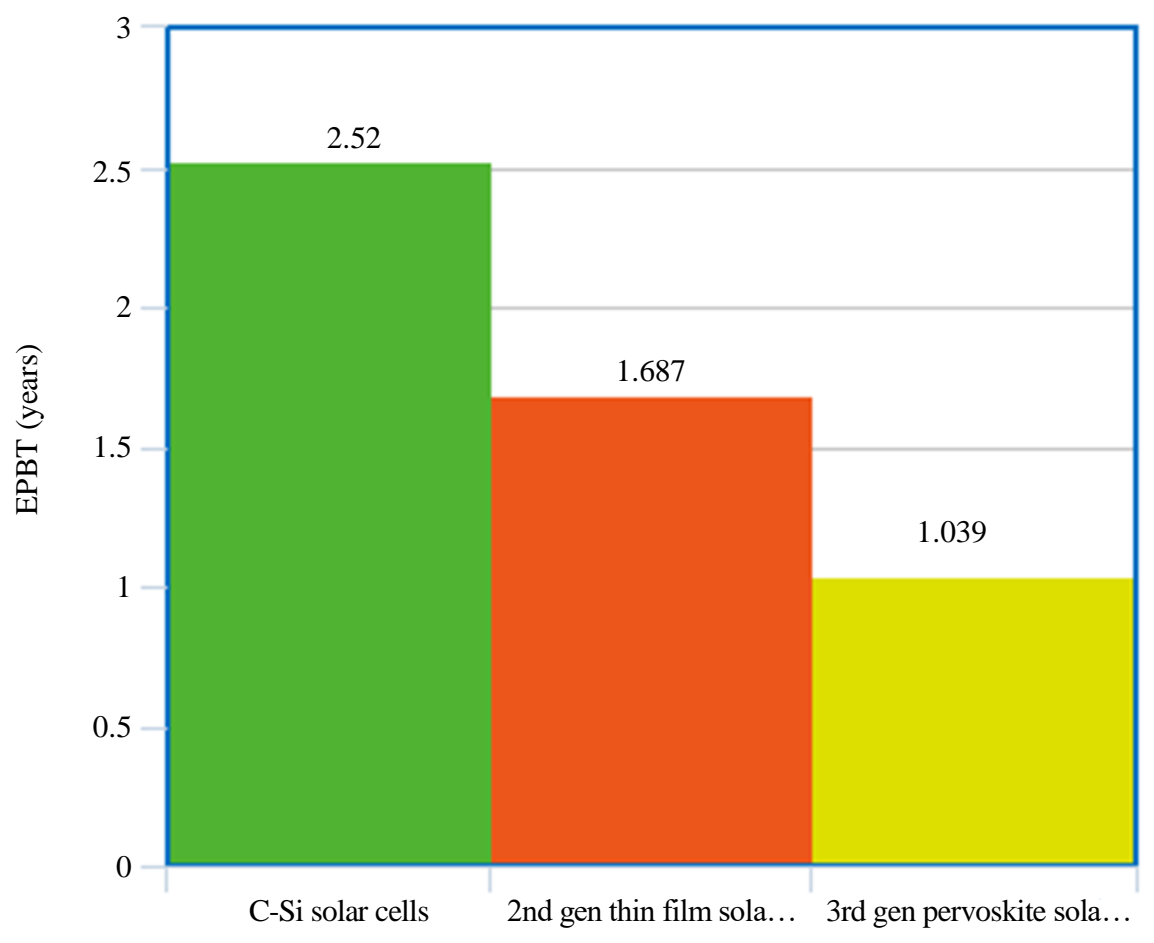

Fig. 3: Represents a variation of the Energy Payback Time (EPBT) with the maturation of the PV technology as the values continue to drop with the progressing generation. The values represent the average energy Payback time of the cells taken over varying efficiency rates 


\section{CdTe Solar Cells}

CdTe has been often addressed as a prime candidate for all the various thin film solar cells. Being an indirect bandgap material like CIGS with large absorption coefficient, its existence as a stable compound has led to the generation of a variety of methods. A thin film of CdTe is adequate to produce the high efficiency cells if the bulk surface recombination is curbed (Lee and Ebong, 2017). The attainment of high conversion efficiency values depends highly on the chlorineactivation step (Major et al., 2016). The success on the part of the CdTe solar cells for the large area module preparation is due to the high chemical stability and the variation of the large variety of successful preparation methods available (Romeo et al., 2018). The bandgap of $1.45 \mathrm{eV}$ observed for CdTe is reckoned as ideal for the absorption of the solar spectrum.

With the research efforts initially being devoted towards improvement of the commercial c-Si solar cells the peak efficiency of the CdTe solar cells stalled at $16.5 \%$, the recent device development started by First Solar, has seen the efficiency values of CdTe surpass that of the multi-crystalline $\mathrm{Si}$ at over $21 \%$ on the lab scale research (Major, 2016). Cadmium Telluride (CdTe) holds the highest module efficiency at $18.6 \%$, amongst the thin film modules as the solar photo-conversion is ideal for its bandgap value which already mentioned stands at $1.45 \mathrm{eV}$. The module production status of CdTe is currently leading the race amongst the likes of a-Si and CIGS thin film solar cell as it can be produced at a cost of $\$ 0.75 / \mathrm{Wp}$ (watt peak) and the production cost at year 2020 was expected to be around $€ 0.5 / \mathrm{Wp}$ (Ong et al., 2018.) The experimental analysis performed by (Rajput et al., 2018) on a $3.2 \mathrm{KW}$ Cadmium Telluride PV system in the composite climate of India. The experiment bore the results where the Energy Payback Time, Energy Production Factor and the Life Cycle Conversion Efficiency as 3.60 years, 0.27 and 0.018 respectively.

\section{Advancement in the Thin Film Technologies}

\section{Perovskite Materials}

This is one of the most progressive thin film technologies which has caught the eyeballs of the world owing to its outstanding PV performance. The ability of the PSC's to generate power with its efficiency being comparable to that of the traditional Silicon solar cells. The efficiency values have risen from 3.8 to $25.2 \%$ within a decade speaks volumes of its potential, (Roy et al., 2020) the same can be analysed from the graphical representation as in Fig. 4. The perovskite materials are characterized by the general $\mathrm{ABX}_{3}$ formula, where $\mathrm{A}$ represents an organic cation, $\mathrm{B}$ is an inorganic cation and $\mathrm{X}$ represents a halide. The variation of the bandgap varies from $\sim 1.6 \mathrm{eV}$ for pure I to $\sim 3.2 \mathrm{eV}$ for pure $\mathrm{Cl}$, the lower band gap materials counting for the better solar cell efficiency values (Lee and Ebong, 2017). The utilization of the Methyl ammonium lead halide $\left(\mathrm{CH}_{3} \mathrm{NH}_{3} \mathrm{PbX}_{3}, \mathrm{X}=\mathrm{Cl}, \mathrm{Br}\right.$ or I) type solar cells has been one of the prominent reasons for the ever increasing values of its Power conversion efficiency. Moreover, the properties like ambipolar transport characteristics, high dielectric constant, low exciton binding energy and intrinsic ferroelectric polarization have been instrumental in this success of the PV cells (Pitchaiya et al., 2020).

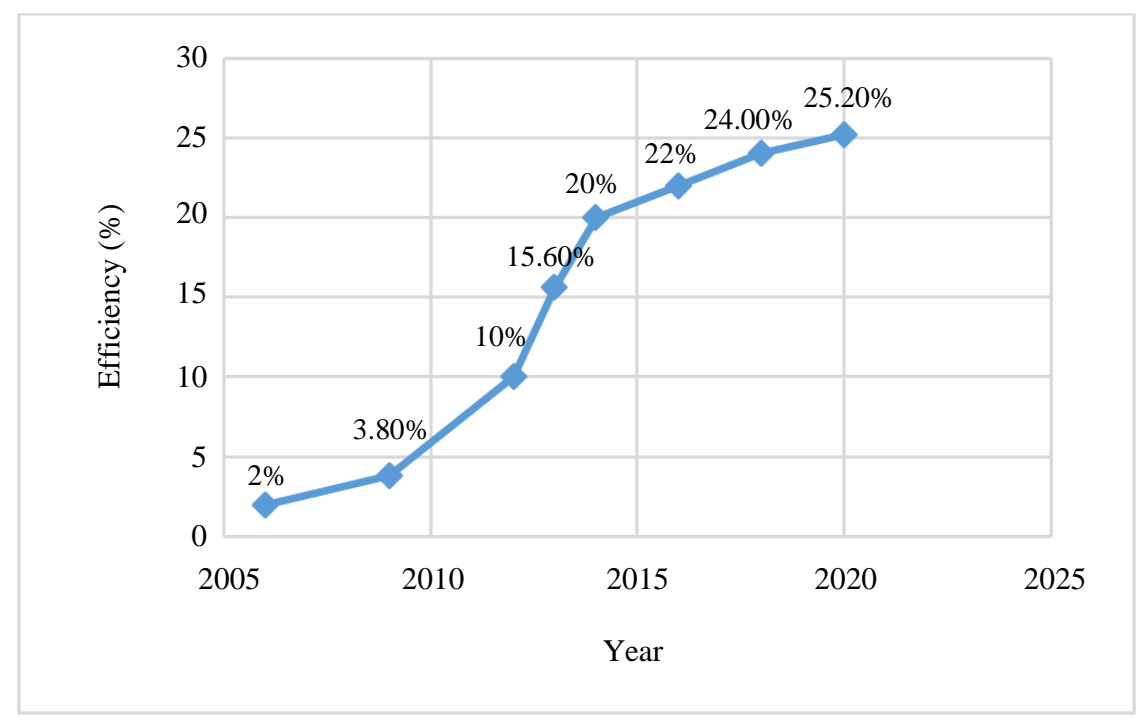

Fig. 4: Is a representation of the rapid development in the power conversion efficiency of the perovskite solar cells since its inception 
The efficiencies have risen from the initial $3.8 \%$ to the present $25.2 \%$ has been observed through the typical material synthesis operations alongside with easy device engineering and solution processability (Roy et al., 2020; Pitchaiya et al., 2020). The variation in the bandgap allows for the absorption of the solar spectra over a wide range and hence corresponds to a high power conversion efficiencies. The analysis performed by (Celik et al., 2017) gives an indication of the energy payback time of the current state of the art devices as it ranges between 7 to 12 months and the EROI of these cells varied from 5.2 to 9.2. Both of these energy indicators set to improve as the PV technology matures with the EBT values to be set as low as 27 days and EROI as high as 105 for high efficiency and long-lifetime devices.

\section{Limitations of Thin Film Solar Cells}

The developments in the thin film technology has not been able to overshadow the limitations that the scientific community is still working hard to overcome. The resource depletion, ecological disturbances and the effect on the human health with the usage of the certain toxic materials are common observations linked with the production of these PV systems. The usage of materials such as In and Ga which are quite scarce and can be a hindrance to the total production capacity of the CIGS thin film solar cells (Kohl et al., 2019). Furthermore the incorporation of the toxic elements like Cadmium and the other rare elements like Indium do constrain its potential as an efficient thin film deployment.

In order to set up a large scale deployment of CdTe based solar cells, a method for the efficient extraction of tellurium needs to be established in order to grow the prospect of the large scale deployment. In order to cover the energy demands of 2050 by CdTe solar cells, require 737,000 metric tons of Cadmium and 786,000 metric tons of tellurium are required (Ong et al., 2018). Likewise, its counterpart CIGS, the use of the poisonous material like Cadmium and the rarity of tellurium pushes the growth of CdTe thin film solar cells a few foot backwards.

The use of lead has been responsible for the toxicity of the perovskite solar cells as lead can cause severe health risks and has a disastrous impact on the ecosystem. This factor creates a negative impact on the users and have reduced the acceptance of the final product (Roy et al., 2020). In order to counter the disastrous impact of lead the other lead-free alternatives are being scoured. Although all the various forms of $\mathrm{Pb}$-free perovskites lag in efficiency in comparison to the hybrid and inorganic perovskites, they demonstrate better structural and environmental stability (Miyasaka et al., 2020).

The alternatives as presented refer to the use of metals like $\mathrm{Sn} 2+, \mathrm{Sn} 4+, \mathrm{Sn} 2+, \mathrm{Ge} 2+, \mathrm{Cu} 2+, \mathrm{Bi} 3+$ and
Sb3+ as stated by (Roy et al., 2020), the toxic lead can be replaced by the mix of $\mathrm{Ba} / \mathrm{Si}$ and $\mathrm{Ba} / \mathrm{Sn}$ to develop environment friendly perovskite materials with excellent properties. MABa ${ }_{0.125} \mathrm{Sn}_{0.875} \mathrm{I}_{3}$ has shown improvement of properties in terms of structural stability and suitable band gap (Sa et al., 2020). Coreshell refractory plasmonic nanoparticles are used in the form of the nano antennas which improve the efficiency of lead-free Perovskite Solar Cells (PSCs) (Mohsen et al., 2020). The photocurrent loss with the parasitic absorption in the hole-conducting layer and the back reflector is quite substantial. In addition to this, the low fill factor values in perovskite solar cells are observed due to a combination of non-uniformity in the absorber (Lee and Ebong, 2017). In the present situation the biggest challenge is to provide the long-term stability, to put the PSC's into the long-term practical application (Wang et al., 2019).

\section{Conclusion}

This study discusses the developments in the thin film PV technologies namely the amorphous silicon solar cells, CdTe and CIGS solar cells. The development of the perovskite-based material thin film solar cells has been analysed as it grows as one of the prominent competitors to the crystalline Si solar cells. The future of solar energy certainly shines brightly with the developments in the solar PV technology and innovative methods to utilize the solar energy. One of those technologies involve the building of the floating PV farms to reduce the burden of the intense land requirements and at the same time using the lakes, lagoons, dams and canals can be an attractive option as discussed by (Sahu et al., 2016). Another such innovation involves the use of the bifacial solar cells which improve the power generated per unit area, the bifacial solar cell technology has started its expansion in the silicon solar cells but very little progress has been reported as it comes down to the thin film solar cells (Phillips et al., 2020). The use of the quantum dots photovoltaics seems to be encouraging for the generation of the high efficiency multi-junction solar cells in addition to the simple room temperature fabrication and the air stable operation (Lee and Ebong, 2017). The growth of the Germanium based solar cells in the military and the commercial satellites where it serves as the bottom layer of the most efficient existing type of solar cells, but its applications for other commercial purposes are restricted owing to the high cost involved in the manufacturing and the processing. Certainly, the future will see efficient methods to use germanium in the commercial solar cells as the technology matures further.

The world seems to be headed in the right path with global summits to preserve the ecosystem and the large investments that are being made in the $\mathrm{R} \& \mathrm{D}$ efforts to 
come up with other efficient energy generation methods stepping out of the reigns of the fossil fuel dominated spell of energy generation. The PV technology has come a long way and is still destined to solve the problems of the mother nature.

\section{Acknowledgement}

The authors would like to thank National Institute of Technology, Tiruchirappalli for providing the necessary platform and support for carrying out this research.

\section{Authors contributions}

Aayush Kumar Choudhary: Preparing the manuscript.

Godwin Glivin: Designing the research plan.

N. Kalaiselvan: Guiding in research.

V. Mariappan and S. Joseph Sekhar: Overall supervision and checking.

\section{Ethics}

This article is original and contains unpublished works. The corresponding author confirms that all of the other authors have read and approved the manuscript with no ethical issues involved.

\section{Conflict of Interest}

The authors declare that they have no Conflict of Interest.

\section{References}

Andreani, L. C., Bozzola, A., Kowalczewski, P., Liscidini, M., \& Redorici, L. (2019). Silicon solar cells: toward the efficiency limits. Advances in Physics: X, 4(1), 1548305.

Battaglia, C., Cuevas, A., \& De Wolf, S. (2016). Highefficiency crystalline silicon solar cells: status and perspectives. Energy \& Environmental Science, 9(5), 1552-1576.

Celik, I., Philips, A. B., Song, Z., Yan, Y., Ellingson, R. J., Heben, M. J., \& Apul, D. (2017). Energy payback time (EPBT) and energy return on energy invested (EROI) of perovskite tandem photovoltaic solar cells. IEEE Journal of Photovoltaics, 8(1), 305-309.

Del Pero, F., Delogu, M., Berzi, L., \& Escamilla, M. (2019). Innovative device for mechanical treatment of End of Life photovoltaic panels: Technical and environmental analysis. Waste Management, 95, 535-548.

Fang, Y., Armin, A., Meredith, P., \& Huang, J. (2019). Accurate characterization of next-generation thinfilm photodetectors. Nat. Photonics, 13(1), 1-4.
Feurer, T., Reinhard, P., Avancini, E., Bissig, B., Löckinger, J., Fuchs, P., ... \& Buecheler, S. (2017). Progress in thin film CIGS photovoltaics-Research and development, manufacturing and applications. Progress in Photovoltaics: Research and Applications, 25(7), 645-667.

Huang, D., \& Yu, T. (2017). Study on energy payback time of building integrated photovoltaic system. Procedia Engineering, 205, 1087-1092.

Kabir, E., Kumar, P., Kumar, S., Adelodun, A. A., \& Kim, K. H. (2018). Solar energy: Potential and future prospects. Renewable and Sustainable Energy Reviews, 82, 894-900.

Kohl, T., de Wild, J., Buldu, D. G., Birant, G., Brammertz, G., Rivas, N. A., ... \& Vermang, B. (2019, June). A study of the degradation mechanisms of ultra-thin CIGS solar cells submitted to a damp heat environment. In 2019 IEEE 46th Photovoltaic Specialists Conference (PVSC) (pp. 1854-1856). IEEE.

Kowsar, A., Farhad, S. F. U., Rahaman, M., Islam, M. S., Imam, A. Y., Debnath, S. C., ... \& Mahmood, Z. H. (2019). Progress in major thin-film solar cells: Growth technologies, layer materials and efficiencies. International Journal of Renewable Energy Research (IJRER), 9(2), 579-597.

Kumar, A., \& Chowdhury, A. (2019). Reassessment of different antireflection coatings for crystalline silicon solar cell in view of their passive radiative cooling properties. Solar Energy, 183, 410-418.

Lee, T. D., \& Ebong, A. U. (2017). A review of thin film solar cell technologies and challenges. Renewable and Sustainable Energy Reviews, 70, 1286-1297.

Major, J. D. (2016). Grain boundaries in CdTe thin film solar cells: a review. Semiconductor Science and Technology, 31(9), 093001.

Major, J. D., Al Turkestani, M., Bowen, L., Brossard, M., Li, C., Lagoudakis, P., ... \& Durose, K. (2016). In-depth analysis of chloride treatments for thin-film CdTe solar cells. Nature communications, 7(1), 1-10.

Mathur, A. S., \& Singh, B. P. (2020). Study of effect of defects on CdS/CdTe heterojunction solar cell. Optik, 164717.

Miyasaka, T., Kulkarni, A., Kim, G. M., Öz, S., \& Jena, A. K. (2020). Perovskite Solar Cells: Can We Go Organic-Free, Lead-Free and Dopant-Free? Advanced Energy Materials, 10(13), 1902500.

Mohsen, A. A., Zahran, M., Habib, S. E. D., \& Allam, N. K. (2020). Refractory plasmonics enabling $20 \%$ efficient lead-free perovskite solar cells. Scientific Reports, 10(1), 1-12.

Muzzillo, C. P. (2017). Review of grain interior, grain boundary and interface effects of $\mathrm{K}$ in CIGS solar cells: Mechanisms for performance enhancement. Solar Energy Materials and Solar Cells, 172, 18-24. 
Ong, K. H., Agileswari, R., Maniscalco, B., Arnou, P., Kumar, C. C., Bowers, J. W., \& Marsadek, M. B. (2018). Review on substrate and molybdenum back contact in CIGS thin film solar cell. International Journal of Photoenergy, 2018.

Phillips, A. B., Khanal Subedi, K., Liyanage, G. K., Alfadhili, F. K., Ellingson, R. J., \& Heben, M. J. (2020). Understanding and Advancing Bifacial Thin Film Solar Cells. ACS Applied Energy Materials.

Pitchaiya, S., Natarajan, M., Santhanam, A., Asokan, V., Yuvapragasam, A., Ramakrishnan, V. M., ... \& Velauthapillai, D. (2020). A review on the classification of organic/inorganic/carbonaceous hole transporting materials for perovskite solar cell application. Arabian Journal of Chemistry, 13(1), 2526-2557.

Rajput, P., Singh, Y. K., Tiwari, G. N., Sastry, O. S., Dubey, S., \& Pandey, K. (2018). Life cycle assessment of the $3.2 \mathrm{~kW}$ cadmium telluride (CdTe) photovoltaic system in composite climate of India. Solar Energy, 159, 415-422.

Ramanujam, J., \& Singh, U. P. (2017). Copper indium gallium selenide based solar cells-a review. Energy \& Environmental Science, 10(6), 1306-1319.

Ramanujam, J., Bishop, D. M., Todorov, T. K., Gunawan, O., Rath, J., Nekovei, R., ... \& Romeo, A. (2020). Flexible CIGS, CdTe and a-Si: H based thin film solar cells: A review. Progress in Materials Science, 110, 100619

Romeo, A., Artegiani, E., \& Menossi, D. (2018). Low substrate temperature CdTe solar cells: A review. Solar Energy, 175, 9-15.

Rossati, A. (2017). Global warming and its health impact. The international journal of occupational and environmental medicine, 8(1), 7 .
Roy, P., Sinha, N. K., Tiwari, S., \& Khare, A. (2020). A review on perovskite solar cells: Evolution of architecture, fabrication techniques, commercialization issues and status. Solar Energy, 198, 665-688.

Sa, R., Zha, W., Ma, Z., Yuan, R., \& Liu, D. (2020). Stable lead-free perovskite solar cells: A first-principles investigation. Spectrochimica Acta Part A: Molecular and Biomolecular Spectroscopy, 118493.

Sahu, A., Yadav, N., \& Sudhakar, K. (2016). Floating photovoltaic power plant: A review. Renewable and sustainable energy reviews, 66, 815-824

Wallace, S. K., Mitzi, D. B., \& Walsh, A. (2017). The steady rise of kesterite solar cells. ACS Energy Letters, 2(4), 776-779.

Wang, R., Mujahid, M., Duan, Y., Wang, Z. K., Xue, J., \& Yang, Y. (2019). A review of perovskites solar cell stability. Advanced Functional Materials, 29(47), 1808843.

Wang, X., Luo, J., Yuan, W., Lin, C. J., Wang, F., Liu, C., ... \& Feng, X. (2020). Global warming accelerates uptake of atmospheric mercury in regions experiencing glacier retreat. Proceedings of the National Academy of Sciences, 117(4), 2049-2055.

Weldekidan, H., Strezov, V., \& Town, G. (2018). Review of solar energy for biofuel extraction. Renewable and Sustainable Energy Reviews, 88, 184-192.

Yoshikawa, K., Kawasaki, H., Yoshida, W., Irie, T., Konishi, K., Nakano, K., ... \& Yamamoto, K. (2017). Silicon heterojunction solar cell with interdigitated back contacts for a photoconversion efficiency over 26\%. Nature energy, 2(5), 17032.

Zaidi, B., Saouane, I., \& Shekhar, C. (2018). Electrical energy generated by amorphous silicon solar panels. Silicon, 10(3), 975-979. 